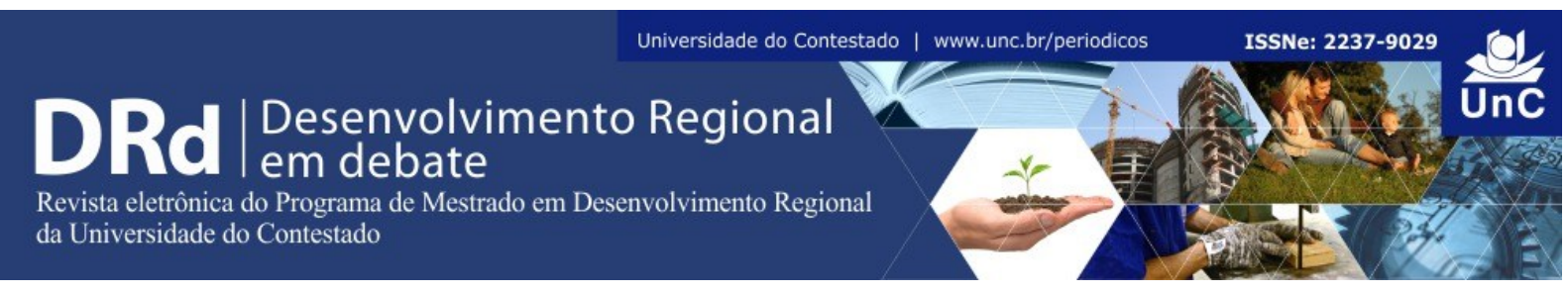

\title{
GOVERNANÇA TERRITORIAL EM EXPERIÊNCIAS DE INDICAÇÃO GEOGRÁFICA: ANÁLISES E PROSPECÇÕES ${ }^{1}$
}

\author{
Cilmara Correa de Lima Fante ${ }^{2}$ \\ Valdir Roque Dallabrida ${ }^{3}$
}

\begin{abstract}
RESUMO
O objeto de análise é a forma como estão organizadas experiências de associativismo territorial, no caso as de Indicação Geográfica, como uma estrutura de governança territorial. Trata-se de redes horizontalizadas, envolvendo conjuntos de organizações, instituições e atores, com atuação territorial. Tomando como referência a estrutura organizacional da Região do Cerrado Mineiro, fazemos análises e inferências sobre uma possível estrutura de governança para a Indicação Geográfica da erva-mate, no Planalto Norte Catarinense e Centro-Sul do Paraná. Conclui-se que, a amplitude do território analisado se apresenta como um dos maiores desafios, exigindo uma estrutura de governança multinível, envolvendo instâncias representativas de caráter local, regional, estadual e interestadual, e multiescalar, atingindo estruturas de representação interestaduais, nacionais e até internacionais, além de conseguir envolver todos os elos da cadeia produtiva da erva-mate, nos dois estados, Santa Catarina e Paraná. No entanto, entendemos que este seja o avanço necessário para a finalização do processo de estruturação da Indicação Geográfica da erva-mate no referido recorte territorial.
\end{abstract}

Palavras chave: Governança Territorial. Erva-Mate. Indicação Geográfica. Planalto Norte Catarinense.

\section{ABSTRACT \\ TERRITORIAL GOVERNANCE IN GEOGRAPHICAL INDICATION OF EXPERIENCES: ANALYSES AND PROSPECTION}

The object of analysis is the way they are organized experiences of territorial associations in the case of the Geographical Indication as a territorial governance system. It is flatter networks involving sets of organizations, institutions and actors with territorial action. With reference to the structure of the organization of the Cerrado Mineiro region, make analyzes and inferences about a possible governance structure for the Geographical Indication of yerba mate, the North Plateau of Santa Catarina and Central-South of Paraná. We conclude that the

\footnotetext{
${ }^{1}$ Uma primeira versão desta abordagem foi preparada para apresentação no $3^{\circ}$ SEDRES - Seminário de Desenvolvimento Regional, Estado e Sociedade (Blumenau - SC - Brasil) e V Encontro Internacional do CONPEDI - Montevidéu - Uruguai (2016).

${ }^{2}$ Graduada em Direito e Mestranda em Desenvolvimento Regional na Universidade do Contestado (UnC). Santa Catarina. Brasil. E-mail: cilmarafante@unc.br

${ }^{3}$ Geógrafo, Doutor em Desenvolvimento Regional, com atuação no Programa de Mestrado em Desenvolvimento Regional da UnC. Santa Catarina. Brasil. E-mail: valdirdallabrida@gmail.com
} 
amplitude of the analyzed territory presents itself as a major challenge facing, requiring a multi-level governance structure, involving representative instances of local, regional, state and interstate character, and multiscale, reaching interstate representation structures, national and even international, plus you get involve all the productive links in the chain of yerba mate, in both states, Santa Catarina and Paraná. However, we understand it to be the breakthrough needed for the finalization of the structuring the process of Geographical Indication of yerba mate in said territorial clipping.

Keywords: Territorial Governance. Mate Herb. Geographical Indication. North Plateau of Santa Catarina.

\section{INTRODUÇÃO}

Nos processos de reconhecimento de uma Indicação Geográfica (IG) deve-se, necessariamente, dar a importância devida à organização dos atores envolvidos. A esses processos de organização que fazemos referência como sua estrutura de governança territorial. Trata-se de formar uma rede colaborativa horizontal com o fim de proceder a articulação, no caso do processo em estruturação, e a gestão, quando a experiência já esteja em funcionamento. Ao falar em Indicação Geográfica, nos referimos a processos de reconhecimento de produtos que se destacam pela sua especificidade territorial e notoriedade.

Como elemento de sustentação teórica para a análise de processos dessa natureza, concebemos governança territorial como um processo de planejamento e gestão de dinâmicas territoriais, focado numa ótica inovadora, partilhada e colaborativa, por meio de relações horizontais (DALLABRIDA, 2015).

Sobre a estrutura de governança territorial, em específico das IG, ao analisarmos a trajetória da experiência da Região do Cerrado Mineiro, onde o produto reconhecido é o café, constata-se uma forte cooperação dos atores locais para a gestão e funcionamento da mesma, graças a uma estrutura de governança territorial que merece destaque. Assim sendo, entendemos que tal experiência pode servir de referência para inspirar a estrutura de governança de experiências que apresentem semelhanças, em termos de tamanho, área de abrangência e/ou tipologia do produto a ser reconhecido como IG.

É em função desse entendimento que neste texto fazemos indicativos de uma possível estrutura de governança territorial para a experiência da IG da erva-mate do Planalto Norte Catarinense e Centro-Sul do Paraná, que está na fase final de estruturação. Pensamos numa estrutura de governança capaz de dar suporte e respaldo ao processo organizativo e futura gestão, envolvendo todos os elos da cadeia produtiva da erva-mate, ou seja, os atores territoriais. Trata-se de uma análise exploratória sustentada em um estudo de caso, a partir do qual fazemos prospecções que poderão servir no processo organizativo da experiência catarinense e paranaense.

O texto, além desta introdução, compreende os aspectos metodológicos, referenciais teóricos sobre governança e Indicação Geográfica, a apresentação das duas experiências de IG, finalizando com análises e prospecções em relação ao caso da erva-mate. 


\section{O CAMINHO METODOLÓGICO}

As análises que pretendemos fazer no presente texto, em primeiro lugar, estão contextualizadas em estudos referentes a um projeto de pesquisa, o qual se propõe analisar vários aspectos de experiências brasileiras e internacionais de Indicação Geográfica. Trata-se do Projeto de Pesquisa Signos Distintivos Territoriais e Indicação Geográfica: um estudo sobre os desafios e perspectivas como alternativa de Desenvolvimento Territorial, o qual conta com a participação de pesquisadores do Brasil, Portugal, Espanha e Argentina. O foco da análise deste texto estará centrado exclusivamente num dos aspectos em estudo no referido projeto: a estrutura de governança territorial.

Em termos de tipo de pesquisa da qual resultou o presente texto, trata-se de uma análise com caráter qualitativo. No entanto, tem característica também de estudo de caso, pois, as análises são feitas a partir de uma experiência, no caso a IG Região do Cerrado Mineiro, já em funcionamento. Prospectivamente, pretendemos utilizar a experiência mineira, como referência para propor indicativos quanto à possível estrutura de governança do caso da erva-mate no Planalto Norte Catarinense e centro-sul do Paraná, já na fase final de estruturação (julho/2016).

O estudo da experiência da IG Região do Cerrado Mineiro foi realizado a partir do acesso aos documentos disponíveis nos órgãos diretivos da associação e cooperativas que compõem a estrutura de governança da IG, além de uma visitação in loco e entrevistas com dirigentes e produtores rurais. Nas entrevistas, o tema foco foi a consulta sobre o processo organizativo, bem como os desafios enfrentados e ainda presentes. A visitação da experiência mineira foi realizada em novembro de 2015.

Já os dados e informações sobre a experiência da erva-mate foram pesquisados em documentos, atas de reuniões, além de constatações in loco, pela participação pessoal em reuniões para a estruturação da $\mathrm{IG}$, nos últimos três anos.

A escolha dessas duas experiências para referir-se ao tema governança territorial se deve ao fato de que, ambas, têm uma característica em comum: são experiências de Indicação Geográfica nas quais o produto objeto de IG está distribuído em áreas territoriais de grande porte e/ou de forma descontínua territorialmente, ou seja, abrangendo vários municípios e até Estados da Federação, como o caso da erva-mate. Essa a razão de se utilizar a atual estrutura de governança territorial da IG Região do Cerrado Mineiro, para se fazer inferências sobre a experiência da erva-mate.

\section{O DEBATE TEÓRICO SOBRE GOVERNANÇA ${ }^{4}$}

Para tratar do tema governança territorial em experiências de Indicação Geográfica (IG) nos deteremos na abordagem teórica sobre governança e governança territorial. No final da abordagem faremos uma reflexão teórico-prática sobre o desafio da gestão de experiências de IG, tomando como referência as concepções sobre governança territorial.

${ }^{4}$ Tema tratado em várias publicações, dentre elas, destacamos Dallabrida (2015). 
Sintetizando contribuições dos principais autores, o conceito de governança, no seu sentido geral, refere-se às redes auto-organizadas envolvendo conjuntos complexos de organizações, instituições e atores provenientes dos setores público e privado (ROSENAU; CZEMPIEL, 1992), como representantes do setor empresarial, dos sindicatos de trabalhadores, da sociedade civil, dos movimentos populares e agentes estatais (KAZANCIGIL, 2002), agindo num processo interativo (STOKER, 1998), cujas interações estão enraizadas e reguladas por regras do jogo negociadas e acordadas pelos seus participantes (RHODES, 1996).

Um conjunto de obras faz referência à governança territorial. Em síntese, estes autores definem governança territorial como: (i) processo de planejamento e gestão de dinâmicas territoriais desenvolvido numa ótica inovadora, compartilhada e colaborativa por meio de relações voluntárias e não hierárquicas de associação entre atores públicos, semipúblicos e privados (FERRÃO, 2013); (ii) novo modo de gestão e decisão dos assuntos públicos num território como modalidade reforçada de bom governo fundamentada simultaneamente no papel insubstituível do Estado, numa concepção mais sofisticada de democracia e num maior protagonismo da sociedade civil (FARINÓS, 2008; ROMERO; FARINÓS, 2011).

Sustentados em parte nas concepções ora explicitadas sobre governança e sua relação com o desenvolvimento territorial, assume-se neste artigo o posicionamento referenciado em Dallabrida (2015, p. 325).

\begin{abstract}
A governança territorial corresponde a um processo de planejamento e gestão de dinâmicas territoriais que dá prioridade a uma ótica inovadora, partilhada e colaborativa, por meio de relações horizontais. No entanto, esse processo inclui lutas de poder, discussões, negociações e, por fim, deliberações, entre agentes estatais, representantes dos setores sociais e empresariais, de centros universitários ou de investigação. Processos desta natureza fundamentam-se num papel insubstituível do Estado, numa noção qualificada de democracia, e no protagonismo da sociedade civil, objetivando harmonizar uma visão sobre o futuro e um determinado padrão de desenvolvimento territorial.
\end{abstract}

Segundo Ferrão (2013), a passagem da ótica de governo a uma ótica de governança não pode ser interpretada como um processo sequencial de natureza radical, em que a segunda substitui a primeira, anulando-a. Mesmo não aparecendo explicitamente nas análises, o que ocorre é a excessiva focalização nas formas e estruturas de governança, não favorecendo a análise mais dialética, centrada na relação que deve existir entre formas de governo e de governança.

Autores, como Moulaert; Parra e Swyngedouw (2014), ressaltam a necessidade da análise interescalar, justificada no reconhecimento da quase impossibilidade que apresenta o nível local para dar conta por si só dos problemas que enfrenta e, por outro lado, no fato de que as relações entre atores em processos de associativismo territorial são cada vez mais do tipo multiescalar, o que exige que a estrutura de governança, também, tenham o caráter multiescalar.

Referindo-se a experiências de associativismo em bairros, no espaço urbano, afirmam os autores que ao falarem em governança procuram atender a um objetivo:

[...] a transformação de relações sociais e estruturas de poder, tanto dentro da comunidade como entre grupos locais e atores externos, com o fim de transformar os estilos de governança em práticas sociais mais inclusivas e democráticas, e criar 
sistemas de participação política multiescalares (MOULAERT, PARRA e SWYNGEDOUW, 2014, p. 19).

Ressaltam, ainda, os autores que nas iniciativas socialmente inovadoras por eles observadas, ao utilizarem proativamente estratégias sociopolíticas multiescalares, foi possível distinguir o atendimento de um conjunto de objetivos, tais sejam: (i) difundir suas práticas inovadoras com o fim de obter o reconhecimento; (ii) organizar mobilizações mais amplas em torno de questões sociais, culturais e políticas; (iii) construir sinergias entre recursos econômicos, sociais, culturais e políticas e, (iv) mobilizar organizações da sociedade civil regionais e nacionais para exercer influência ou pressão sobre instituições estatais, com vistas ao atendimento de seus pleitos (MOULAERT, PARRA e SWYNGEDOUW, 2014).

No entanto, mesmo reconhecendo a importância da esfera pública onde ocorrem processos de governança, seja do tipo territorial ou multiescalar, o Estado continua desempenhando um papel importante. São questões relativas ao papel do Estado: (i) fomentar contratos coletivos entre organizações da sociedade civil e órgãos públicos; (ii) concentrar esforços em iniciativas socialmente inovadoras ativas e interescalares, no lugar de optar por políticas tradicionais, mesmo que propostas pela ação coletiva territorial; (iii) estabelecer redes de iniciativas de inovação social escalares - cruzadas e interescalares -, com as ações da escala territorial ou nacional; (iv) criar pontos de acesso direto às agências estatais estaduais e nacionais (MOULAERT, PARRA e SWYNGEDOUW, 2014).

Já Pereira (2014) afirma, com base na realidade socioeconômica e política portuguesa, que um Estado fraco favorece a concentração da riqueza e acentua a desigual partilha de recursos, as desigualdades sociais e o desequilíbrio dos territórios. No entanto, estruturas de governança territorial multinível ainda se constituem um desafio nas sociedades contemporâneas, já que o conceito, consensual nos seus princípios, revela debilidades na sua aplicação. Para a autora, a governança multinível está consensualizada como o modelo mais eficaz e eficiente para a governabilidade dos territórios, por que: (i) gere melhor os impactes territoriais a várias escalas, provocados por externalidades multiescalares; (ii) reflete a diversidade de interesses dos cidadãos; (iii) facilita compromissos políticos mais credíveis e (v) fomenta a inovação e experimentação no campo das políticas públicas (PEREIRA, 2014). A razão principal de se obter estruturas de governança multinível é a multiplicação de atores, o que implica na estruturação de redes de governança, a fim de garantir a articulação entre os envolvidos.

Citando Torfing (2005), Pereira (2014) afirma que as redes de governança potenciam ganhos em eficiência, em especial por meio da: (i) identificação de problemas e oportunidades, produzindo soluções flexíveis que permitem o seu ajustamento consoante à complexidade e variedade dos problemas, isto é, favorecem a governança proativa; (ii) partilha e agregação de informação e conhecimento entre atores, que se transformam numa mais-valia na formulação de políticas; (iii) estabelecimento de um quadro para a formação de consensos ou para a minimização dos conflitos entre atores; (iv) redução do risco de resistência dos atores à implementação das políticas acordadas.

A autora conclui suas análises, com base na realidade portuguesa, afirmando que num mundo global, a governança multinível impôs-se aos territórios. No entanto, ressalta que: "Na teoria, esta participação mais alargada traduz-se num reforço da democracia e do princípio da subsidiariedade, assegurando uma maior proximidade entre a autoridade do Estado e os cidadãos e uma valorização das regiões e das comunidades locais" (PEREIRA, 2014, p. 17).

DRd - Desenvolvimento Regional em debate (ISSNe 2237-9029) 
No entanto, na prática observada pela autora, o reforço da democracia possível de ser proporcionada por estruturas de governança parece não estar assegurada em duas dimensões: por um lado, o poder do Estado está fortemente condicionado por entidades externas; por outro, o Governo tem criado estruturas de governança regionais que reforçam poderes que não têm a legitimação do voto, o requisito base da democracia.

Esse risco apontado pela autora, no caso de Portugal, é um alerta para outros países, mesmo o Brasil e, em especial, o caso de Santa Catarina, com as antigas Secretarias de Desenvolvimento Regional, transformadas atualmente em Agências Regionais de Desenvolvimento.

Por outro lado, o debate sobre governança territorial e governança multinível, ou multiescalar, não são noções contraditórias. A governança territorial, assim como a concebemos, admite a ação multiescalar, no entanto, partindo da dinâmica territorial. Também admite a governança multinível e/ou multissetorial, pois, trata-se de processos em que estão envolvidos atores sociais, empresariais e estatais, estes últimos, de instâncias nacional, estadual, regional ou municipal, indistintamente. Portanto, mesmo que autores admitam essa contraditoriedade, são pontos de vista que merecem mais discussão. O importante é que ao definir governança territorial (DALLABRIDA, 2015), se admita que as ações compartilhadas e horizontais, que se estabelecem territorialmente entre atores diferenciados resultam de iniciativas ou têm intervenções do tipo intra, inter e supraterritorial.

Relacionando o debate sobre governança territorial ao processo de organização de uma IG, é fundamental destacar que a função primordial da estrutura de governança de uma IG é estabelecer regras coletivas, fortalecendo os vínculos entre os atores envolvidos. Isso gera laços de dependência recíproca, como resultado de ações que visem o atendimento do bem comum, o que se converte na base da ação coletiva.

São, ao mesmo tempo, as possibilidades e desafios que se interpõem na efetivação dos processos de governança territorial.

\section{INDICAÇÃO GEOGRÁFICA: CONCEPÇÃO, TIPOLOGIAS E A QUESTÃO DA ESTRUTURA DE GOVERNANÇA}

O reconhecimento de um produto com IG se trata de uma estratégia de qualificação, valorizando a diversidade e a singularidade de produtos enraizados em territórios específicos, como um componente catalisador de novas dinâmicas de desenvolvimento territorial, podendo ser entendido como um processo de inovação institucional (NIEDERLE, 2014).

A legislação brasileira sobre Propriedade Intelectual $^{5}$ que regulamenta as Indicações Geográficas é relativamente recente, por conta da ratificação do Brasil ao acordo TRIPS ${ }^{6}$, tendo passado a vigorar desde 1996.

\footnotetext{
${ }^{5}$ Lei n ${ }^{\mathrm{o}} .9 .279$ de 14 de maio 1996.

${ }^{6}$ TRIPS (Trade-Related Aspects of Intellectual Property Rights) é um tratado de comércio sobre os direitos de propriedade intelectual da Organização Mundial do Comércio (OMC).
} 
A Convenção da União de Paris (CUP) considera a Indicação Geográfica como sendo propriedade industrial, além de tratar da repressão à concorrência desleal. A TRIPS se refere ao comércio de bens com diferenciais protegidos por mecanismos de propriedade intelectual. A Constituição Federal de 1988 assegura aos autores de inventos industriais privilégio temporário para sua utilização, bem como proteção às criações industriais, à propriedade das marcas, aos nomes de empresas e a outros signos distintivos. A Lei de Propriedade Industrial refere-se aos direitos e deveres referentes à propriedade industrial no Brasil. Por fim, a instrução normativa $n^{0}$ 25/2013 (INPI) estabelece o procedimento para registro das Indicações Geográficas no Brasil.

A Lei de Propriedade Industrial estabelece que as Indicações Geográficas se dividem em Indicação de Procedência e Denominação de Origem. Considera-se Indicação de Procedência o nome geográfico de país, cidade, região ou localidade de seu território, que se tenha tornado conhecido como centro de extração, produção ou fabricação de determinado produto ou de prestação de determinado serviço. Já Denominação de Origem é considerada o nome geográfico de país, cidade, região ou localidade, que designe produto ou serviço cujas qualidades ou características se devam exclusiva ou essencialmente ao meio geográfico, incluídos fatores naturais e humanos.

A par disso, é possível destacar dois aspectos, a qualidade ou característica que designem o produto e a exclusividade ou essencialidade do meio geográfico, incluídos fatores naturais e humanos. Em outras palavras, na Denominação de Origem não basta que o produto tenha se tornado conhecido pelas pessoas como de determinado local, é imprescindível que suas características sejam únicas devido às condições geográficas e/ou inclusive devido ao savoir faire ${ }^{7}$.

Pimentel (2013) explica que a Indicação de Procedência compreende a Indicação Geográfica que tenha se tornado conhecida como centro da fama de um determinado produto, e a Denominação de Origem é a Indicação Geográfica que designa o próprio produto. Igualmente, a proteção estender-se-á à representação gráfica ou figurativa da Indicação Geográfica, bem como à representação geográfica de país, cidade, região ou localidade de seu território cujo nome seja Indicação Geográfica ${ }^{8}$.

Importante restrição traz o art. 180 da Lei de Propriedade Industrial, ao estabelecer que não será considerado Indicação Geográfica o nome geográfico que tiver se tornado comum, utilizado corriqueiramente para designar produto ou serviço. Além disso, a lei restringe o uso da Indicação Geográfica aos produtores e prestadores de serviço estabelecidos no local, garantindo-lhes exclusividade. É exigido também o atendimento de requisitos de qualidade, quando se tratar de Denominação de Origem.

A proteção jurídica, em primeiro lugar, visa impedir terceiros, que não cumprem os requisitos legais, de fabricar, importar, exportar, vender, expor ou oferecer à venda

\footnotetext{
${ }^{7}$ Savoir-faire é um termo francês utilizado amplamente em vários segmentos para designar o conhecimento específico na realização de uma tarefa prática ou na solução de um problema prático. Pode ser utilizado tanto para pessoas como para instituições e empresas. Savoir-faire é a experiência prática na realização de uma tarefa, isto é, a capacidade de realização com êxito utilizando conhecimento de como executar alguma tarefa, sendo equivalente ao termo habilidade prática ou ao termo tecnologia, mas difere dos termos conhecimento tácito ou know-how que são obrigatoriamente difíceis de transferir o saber, enquanto o savoir-faire pode ou não pode ser difícil a transferência deste saber prático.

${ }^{8}$ Art. 179 da Lei 9.279/1996.
} 
ou ter em estoque produto que se apresente como IG. A proteção jurídica, em segundo lugar, impede terceiros de usar, em produto, recipiente, invólucro, cinta, rótulo, fatura, circular, cartaz ou em outro meio de divulgação ou propaganda, termos retificativos, tais como tipo, espécie, gênero, sistema, semelhante, sucedâneo, idêntico, ou equivalente, não ressalvando a verdadeira procedência do produto. $\mathrm{E}$, em terceiro lugar, impede terceiros de usar marca, nome comercial, título de estabelecimento, insígnia, expressão ou sinal de propaganda ou qualquer outra forma que indique procedência que não a verdadeira, ou vender ou expor à venda produto com esses sinais (PIMENTEL, 2013, p. 137).

Com relação à legitimidade para requerer o registro da Indicação Geográfica, dispõe o art. $5^{\circ}$ da Instrução Normativa $n^{\circ} 25 / 2013$ (INPI) que as associações, os institutos e as pessoas jurídicas representativas da coletividade legitimada ao uso exclusivo do nome geográfico estabelecidas no respectivo território podem realizar o pedido na condição de substitutos processuais. Por outro lado, no caso de um único produtor ou prestador de serviço ser legitimado para o uso do nome geográfico, seja pessoa física ou jurídica, pode pleitear o registro em nome próprio ${ }^{9}$. Em se tratando de nome geográfico estrangeiro já reconhecido como Indicação Geográfica no seu país de origem ou reconhecido por entidades ou organismos internacionais competentes, o registro deverá ser requerido pelo titular do direito sobre a Indicação Geográfica ${ }^{10}$.

Em processos para o reconhecimento de uma Indicação Geográfica deve-se, necessariamente, focar a atenção na organização dos atores envolvidos. Nesse sentido, é fundamental a organização coletiva com o fim de formar uma rede colaborativa horizontal.

Importante destacar os apontamentos de Pimentel (2013, p. 138):

A organização (dos produtores) tem por base o acordo coletivo de qualidade do produto que requer um processo produtivo cujos métodos e técnicas, geralmente tradicionais, passam dos pais aos filhos ou parentes, outras vezes por sucessão empresarial. Esse processo vai desde o cuidado com a matéria-prima, passando pela boa conservação e armazenagem, industrialização, embalagem e distribuição, até chegar ao consumidor. O processo produtivo de uma IG de produtos está cada vez mais condicionado às exigências da rastreabilidade, sejam os produtos destinados para alimentação ou para qualquer outro uso. As características familiares e tradicionais da IG se relacionam com a satisfação do produtor, ao ver que o comércio valoriza o território e a técnica tradicional na elaboração do produto, elementos que compõem juntamente com uma qualidade ímpar a vantagem na concorrência com outros produtos de qualidade inferior ou que não desfrutam da mesma notoriedade.

Após a identificação de um produto potencial para se pleitear o registro, deve-se realizar um estudo da região e avaliar se o produto em questão realmente poderá se tornar uma Indicação Geográfica. Vejamos algumas recomendações contidas em documento oficial do Ministério da Agricultura, Pecuária e Abastecimento (MAPA) ${ }^{11}$.

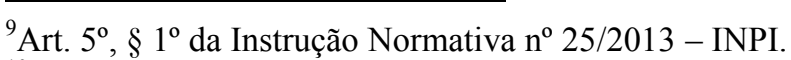

${ }^{10}$ Art. $5^{\circ}, \S 2^{\circ}$ da Instrução Normativa $n^{\circ} 25 / 2013$ - INPI.

${ }^{11}$ Guia para solicitação de registro de indicação geográfica para produtos agropecuários. Coordenação de Incentivo à Indicação Geográfica de Produtos Agropecuários - CIG/DEPTA/SDC/MAPA Esplanada dos Ministérios Bloco D anexo A sala 244 Brasília- DF, p. 8. Disponível em $<$ http://www.agricultura.gov.br/> Acesso em: 10 de maio de 2015.
} 


\begin{abstract}
A primeira etapa a ser avaliada é a organização dos produtores com intuito de construir o processo de reconhecimento da IG. A IG necessita de um forte envolvimento e participação dos produtores e/ou dos transformadores, assim como das outras pessoas envolvidas na sua gestão. A atuação é voluntária e coletiva, ou seja, se apoia em uma associação. O termo "associação" neste contexto será correspondente a qualquer organização de produtores e/ou transformadores relacionados com o produto, seja qual for sua forma jurídica ou sua composição. [...] A segunda etapa é fazer um levantamento histórico cultural da região. Devem-se buscar informações e elementos que comprovem que a região tem notoriedade para se tornar uma IG. É importante o levantamento de evidências concretas deste reconhecimento. Informações em reportagens de jornais, entrevistas, fotografias, livros, etc. podem demonstrar desde quando a região passou a ser conhecida pela produção do produto em estudo. Este levantamento servirá de base para a elaboração de estudos mais detalhados para a delimitação da área geográfica da IG. A delimitação geográfica considerará aspectos diferenciados quando para indicação de procedência ou denominação de origem, exigindo estudos específicos diferenciados e mais complexos para as denominações de origem. [...] A terceira etapa é a caracterização do produto e garantia da sua qualidade. Deve-se definir e documentar cada etapa do processo de produção com o objetivo de garantir a tipicidade do produto. Todos os métodos de verificação e rastreabilidade, as características do produto, até a forma de apresentação ao consumidor devem ser descritos com detalhe. Este detalhamento deverá ser definido e acordado entre os produtores e comporá as regras que deverão ser seguidas pelo produtor, estabelecido dentro da área delimitada, para poder usar o selo de IG em seu produto. [...] A quarta e última etapa é a criação de um Conselho Regulador. Este Conselho deverá orientar e controlar a produção, elaboração e a qualidade dos produtos amparados pela IG conforme as regras definidas no passo anterior.
\end{abstract}

Importante destacar que o registro das indicações geográficas é de natureza declaratória, uma vez que implica no reconhecimento de condições pré-existentes, seja da reputação ou da influência do meio geográfico no produto.

Relacionando o debate teórico sobre governança territorial com o processo organizativo de uma IG, Dallabrida (2016), resume Vandecandelaere et al. (2011), destacando aspectos da ação coletiva no estabelecimento da estratégia de valorização do produto, objeto principal de uma IG: (i) definir as pessoas ou setores que se beneficiarão do direito; (ii) criar uma rede e associações no sistema de produção local, ou externamente; (iii) definir as regras que os produtores deverão compartilhar nas diferentes fases. Já para que a ação coletiva seja capaz de mobilizar os atores territoriais, na mesma obra são feitas as seguintes recomendações: (i) organização da rede local, com o propósito de intercambiar pontos de vistas sobre o produto e suas características; (ii) empoderamento dos atores desfavorecidos, para que possam participar do processo de forma indistinta com os demais atores, fator crucial para a sustentabilidade social do processo de criação do valor, ação que se recomenda seja efetuada pelas administrações públicas, organizações não governamentais e/ou universidades; (iii) fazer a mediação, pois cada ator envolvido tem uma ideia acerca do produto e sua evolução, a fim de considerar os motivos próprios.

Estudos comparados realizados entre experiências de IG brasileiras e portuguesas constataram a permanência de intensas dificuldades de produtores, artesãos ou empresários trabalharem e se relacionarem associativamente. Avaliando várias experiências, o estudo conclui que a estrutura de governança territorial mais adequada para a inserção no mercado dos produtos com especificidade territorial, ainda é uma questão em aberto (DALLABRIDA, 2016).

DRd - Desenvolvimento Regional em debate (ISSNe 2237-9029) 
Assim, na tentativa de continuar a reflexão sobre esses desafios, entendemos oportuna uma análise, amparada na trajetória da experiência da IG Região do Cerrado Mineiro, onde se observa uma forte cooperação dos atores locais para a gestão e funcionamento da mesma, sustentada numa complexa e interessante estrutura de governança territorial. Isso motivou fazermos analogias com a experiência da IG da erva-mate no Planalto Norte Catarinense e Centro-Sul do Paraná, mesmo que ainda em pleno processo de reestruturação. Sobre a experiência mineira, a seguir, fazemos uma breve caracterização.

\section{CONTEXTUALIZAÇÃO DA IG REGIÃO DO CERRADO MINEIRO}

Região do Cerrado Mineiro é uma IG) para café, que foi reconhecida pelo Instituto Nacional de Propriedade Industrial (INPI) como Indicação de Procedência em 2005. Já, a partir de 2011, recebeu o reconhecimento como Denominação de Origem para café verde em grão e industrializado em grão ou moído, sendo a espécie coffea arábica a oficial. Trata-se da primeira região brasileira produtora de café a obter tal reconhecimento como IG.

Dentre os fatores relacionados a essa IG destaca-se a estrutura organizacional existente na região ${ }^{12}$, bem como o programa de certificação, que garante segurança aos compradores e agrega valor ao produto. Salienta-se também a relevância da proteção do nome geográfico aos produtores de café da Região do Cerrado Mineiro no cenário internacional.

\section{DADOS SOBRE LOCALIZAÇÃO E FATORES EDAFOCLIMÁTICOS}

A região delimitada pela referida IG abrange 55 municípios, aproximadamente 4.500 (quatro mil e quinhentas) propriedades e 3.500 (três mil e quinhentos) produtores, em cerca de 155.000 (cento e cinquenta e cinco mil) hectares de café aptos a receberem o status de uma Indicação Geográfica, conforme é possível ver na Figura 1.

O território da Região do Cerrado Mineiro é caracterizado pela definição das estações climáticas, com verão quente e úmido e inverno seco e ameno, temperaturas médias de $18^{\circ}$ a $23^{\circ}$, altitude da área de produção de 800 a 1.250 metros, sem a ocorrência de geadas.

Os fatores edafoclimáticos permitem floradas intensas e únicas, maturação uniforme e colheita concentrada, proporcionando a produção de cafés de alta qualidade, com aromas intensos, que variam do caramelo a nozes, com acidez delicadamente cítrica e sabor achocolatado de longa duração.

\footnotetext{
${ }^{12}$ Neste texto consideraremos a estrutura organizacional da IG, como a estrutura de governança territorial da referida experiência, conforme adiante fazemos referência.
} 
Figura 1- Localização da IG de café Região do Cerrado Mineiro

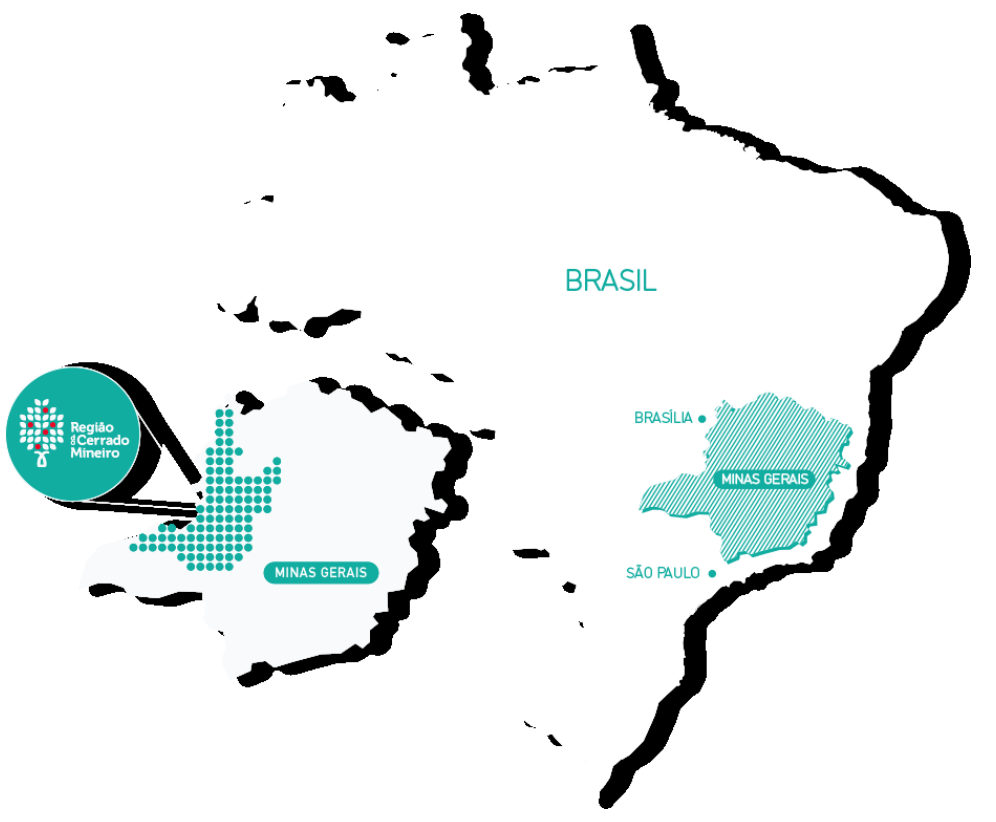

Fonte: Banco de Dados da Federação dos Cafeicultores do Cerrado (2015)

\section{TRAJETÓRIA DA REGIÃO DO CERRADO MINEIRO}

A trajetória da Região do Cerrado Mineiro teve início na década de 1970, sendo este um momento de mudanças na cafeicultura nacional, dados os problemas climáticos enfrentados nas tradicionais regiões produtoras, como São Paulo e norte do Paraná, com a incidência de geadas que danificaram as plantações de café. Devido a tal fato, o governo lançou um plano de revigoramento dos cafezais e incentivou a exploração de novas regiões com condições climáticas e geográficas favoráveis à cultura do café. Dessa forma, o Cerrado Mineiro, demonstrou capacidade para desenvolver esta nova cultura. Como consequência desta medida, vários produtores, oriundas de diversas partes do Brasil - em especial Paraná e São Paulo - enxergaram o potencial da Região e começaram a plantar suas primeiras lavouras.

A diversidade de produtores atrelada ao pioneirismo e espírito empreendedor, foi essencial ao desenvolvimento da referida região mineira, uma vez que crises de ordem financeira e estrutural na cadeia do café abalaram a atividade como um todo no decorrer dos anos 1980 e 1990. No entanto, foi nesse momento de adversidade que a Região do Cerrado Mineiro cresceu, se estruturou e deu mostras de sua força. A partir dos anos 1990 os produtores se organizaram, em associações, cooperativas, até formarem um Conselho, à época denominado Conselho das Associações dos Cafeicultores do Cerrado (CACCER), atualmente a Federação dos Cafeicultores do Cerrado, em um sistema organizacional inovador de gestão de interesses coletivos.

Em 2011 o "Café do Cerrado", marca que então representava essa região produtora, a qual teve seu pedido de registro solicitado em 1993, e concedido em 2005 pelo INPI, foi revista e passou por uma remodelação. Focou-se então na expressão "Região do Cerrado 
Mineiro"13, reconhecida naquela época como Indicação de Procedência e devidamente registrada como marca na União Europeia, Japão e requerida a proteção nos Estados Unidos. Com essa nova determinação do INPI, a Região do Cerrado Mineiro passou a ser protegida e reconhecida como Denominação de Origem. Os pilares da estratégia de Marca da Denominação de Origem Região do Cerrado Mineiro são: integrar, desenvolver e conectar.

\section{A ESTRUTURA ORGANIZACIONAL DA IG REGIÃO DO CERRADO MINEIRO}

Como já fizemos referência, um dos aspectos de destaque da IG Região do Cerrado Mineiro é sua estrutura organizacional, que aqui referimos como estrutura de governança territorial da referida experiência. A estrutura básica da IG é formada pela Federação dos Cafeicultores do Cerrado, a Fundação de Desenvolvimento do Cerrado Mineiro, o Centro de Excelência do Café do Cerrado, as associações e cooperativas de produtores.

Figura 2 - Estrutura de Governança da IG Região do Cerrado Mineiro

\section{Sistema organizacional}

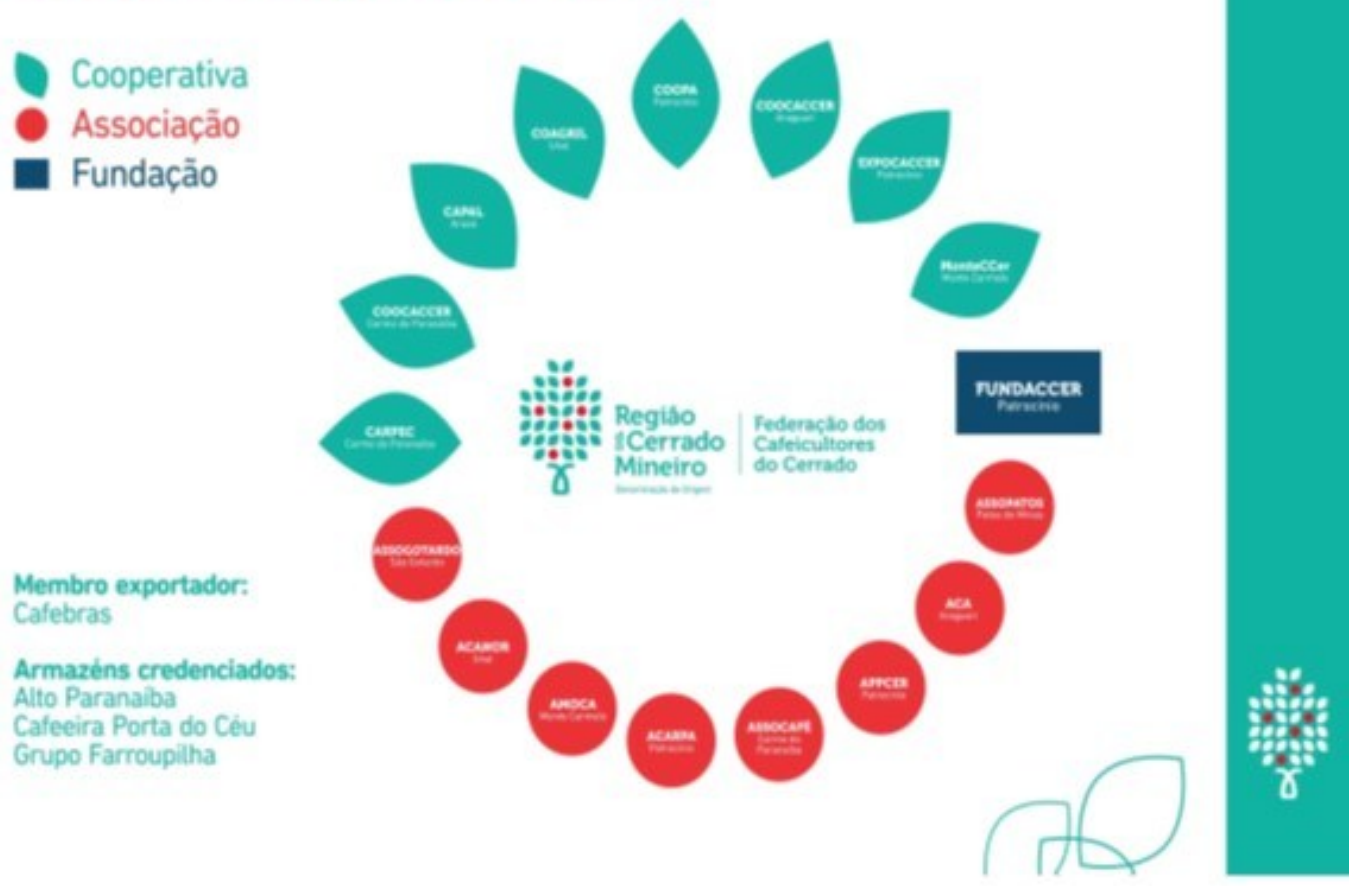

Fonte: Banco de Dados da Federação dos Cafeicultores do Cerrado (2015)

\footnotetext{
${ }^{13}$ Conforme a Portaria n ${ }^{\circ} 561$, de 17 de dezembro de 2002, o Diretor-Geral do Instituto Mineiro de Agropecuária (IMA), Célio Gomes Floriani, determinou que: “Art.1 - Fica alterada a denominação da região para produção de café no Estado de Minas Gerais, a que se refere o artigo $1^{\circ}$ da Portaria $n^{\circ} 165$, de 27 de abril de 1995, de "Região dos Cerrados de Minas" para "Região do Cerrado Mineiro". Art. $2^{\circ}$ - Esta Portaria entra em vigor na data de sua publicação, revogando as disposições em contrário".
} 
Na Figura 2, podemos ver uma representação da estrutura de governança territorial da IG Região do Cerrado Mineiro, com suas subestruturas.

A Federação dos Cafeicultores do Cerrado ${ }^{14}$, nova denominação para o Conselho das Associações dos Cafeicultores do Cerrado (CACCER), representa a estrutura de poder maior da IG. Seu papel consiste em representar, controlar e promover a origem, os produtores, a qualidade dos produtos e a utilização da Denominação de Origem "Região do Cerrado Mineiro". A Federação passa assim a ser a detentora oficial do logotipo da marca "Região do Cerrado Mineiro" no Brasil e em diversos países, e a representante processual da Indicação Geográfica, nas modalidades Indicação de Procedência e Denominação de Origem, no Brasil.

A Federação é uma entidade sem fins lucrativos, organizada e estruturada por um grupo composto por oito associações de produtores, oito cooperativas e uma Fundação. Sua sede administrativa está localizada no município de Patrocínio (MG), Brasil. Gestora e detentora da marca Café do Cerrado, é o organismo responsável pela coordenação das ações de marketing e representação institucional da região.

As associações e cooperativas são entidades independentes, As associações são membros institucionais, enquanto as cooperativas assumem um caráter comercial. O Conselho de Administração da Federação é formado pelos presidentes de cada entidade filiada, de forma que as decisões tomadas pelo conselho têm rápida repercussão nas associações e cooperativas, num modelo denominado por eles de Sistema de Rede.

Como estrutura complementar, em 1999 foi criada a Fundação de Desenvolvimento do Cerrado Mineiro (Fundacer) e o Centro de Excelência do Café. A Fundacer tem por missão estabelecer linhas de pesquisa e desenvolvimento para a produção, identificação e ampliação da produção de cafés especiais, notadamente o café da Região do Cerrado Mineiro. Possui importantes alianças com universidades brasileiras e centros de pesquisa nacionais e internacionais. A Fundação é mantenedora do Centro de Excelência do Café do Cerrado (CEC), que tem por objetivo proporcionar a constante elevação dos padrões tecnológicos da cultura cafeeira na Região do Cerrado Mineiro. Cabe ao CEC promover o intercâmbio permanente de experiências com técnicos e especialistas de diversas regiões produtoras, executando cursos e eventos em suas estruturas. A CEC tem sua estrutura física no município de Patrocínio (MG), com uma área construída de dois mil metros quadrados.

Como é possível perceber, a estrutura de governança territorial da IG Região do Cerrado Mineiro, tem algo de inovador em relação a outras experiências similares no Brasil e no mundo. Conta na sua formação, com institucionalidades que atuam em diferentes dimensões: (a) a Federação, como instituição de representação superior; (b) as associações de produtores, como instituições de representações de base (os produtores); (c) duas instituições de apoio ao setor produtivo, uma com caráter de pesquisa tecnológica - a Fundacer - e outra de promoção, extensão tecnológica, capacitação de produtores (cursos e evento), no caso o Centro de Excelência do Café do Cerrado; (d) por fim, instituições de caráter comercial, como o caso das cooperativas de produtores e outras empresas comerciais, tais como, a Cafebras e armazéns credenciados.

${ }^{14}$ Neste texto, passaremos a denominar Federação. 
Na sequência, com base nas informações referentes à contextualização da IG Região do Cerrado Mineiro, faremos analogias com outra experiência de IG que está na fase de estruturação, o caso da erva-mate da região Planalto Norte Catarinense e centro-sul do Paraná.

\section{CONTEXTUALIZAÇÃO DE EXPERIÊNCIA DE IG DA ERVA-MATE: ANÁLISES E PROSPECÇÕES}

Iniciamos esta parte do texto contextualizando a situação de uma experiência de IG em construção, o caso da erva-mate do Planalto Norte Catarinense e Centro Sul do Paraná ${ }^{15}$. Na sequência, com base na estrutura de governança territorial da IG Região do Cerrado Mineiro, faremos prospecções sobre a experiência da erva-mate.

A erva-mate foi a atividade econômica extrativa mais importante do final do século XIX até por volta de 1970 para a chamada Região do Contestado, estendendo-se por todo sul do vale do Rio Negro, o qual serve como divisor físico entre os Estados de Santa Catarina e Paraná, na sua porção central. Esta região corresponde, aproximadamente, ao Planalto Norte Catarinense e Centro Sul do Paraná, recorte territorial definido para as análises realizadas neste artigo.

Atualmente a atividade ervateira continua importante, não no sentido de ser a atividade econômica maior geradora de renda regional, mas pelo seu papel de complementação de renda de pequenos produtores rurais, além de contribuir para a preservação de grandes áreas de remanescentes da Floresta Ombrófila Mista, onde a ervamate e a araucária são duas das principais espécies vegetais. Com isso, mais de $80 \%$ da ervamate produzida na região provem de áreas integradas à vegetação, fato que a torna conhecida como erva-mate nativa (DALLABRIDA, 2012).

Quanto ao produto a ser reconhecido, segundo estudos já realizados, trata-se da ervamate nativa produzida na região nas suas diferentes formas de utilização, tais como: erva mate para chimarrão; chás a base da erva mate; erva mate para sucos, refrigerantes, energéticos ou outras bebidas; erva mate para uso culinário, farmacêutico, cosmético e na indústria química em geral (DALLABRIDA et al. 2014).

Na Figura 3, é possível localizar a região ervateira em referência, abrangendo parte dos estados de Santa Catarina e Paraná. É o recorte territorial conformado pelo médio vale do Rio Iguaçu e seus afluentes.

Mesmo que o processo de estruturação da IG da erva-mate já esteja na fase final, em relação à estrutura de governança, temos dois atores principais que precisam estar envolvidos: os produtores, na grande maioria pequeno produtor e o setor industrial e comercial. O setor empresarial está representado no processo de debate e estruturação da IG através do Sindicato da Indústria do Mate, presente tanto em Santa Catarina, como no Paraná e Rio Grande do Sul, estados brasileiros que concentram a produção e industrialização da erva mate no Brasil. Quanto aos produtores, os mesmos se agregam em sindicatos de trabalhadores rurais, no

\footnotetext{
${ }^{15}$ Mesmo que ainda, neste momento do processo de estruturação, o debate esteja centralizado no recorte territorial do PNC, nossa proposta é que se avance, ampliando a área de abrangência, integrando a região produtora do Centro Sul do Paraná, conforme identificado na Figura 3.
} 
entanto, não há no momento associações de pequenos produtores, em especificamente entre produtores de erva-mate (DALLABRIDA et al., 2014). O agente articulador desta estruturação, é a Empresa de Pesquisa Agropecuária e Extensão Rural do Estado de Santa Catarina (EPAGRI), regional de Canoinhas.

Figura 3 - Região do Planalto Norte Catarinense e Centro-Sul do Paraná com incidência de ervais

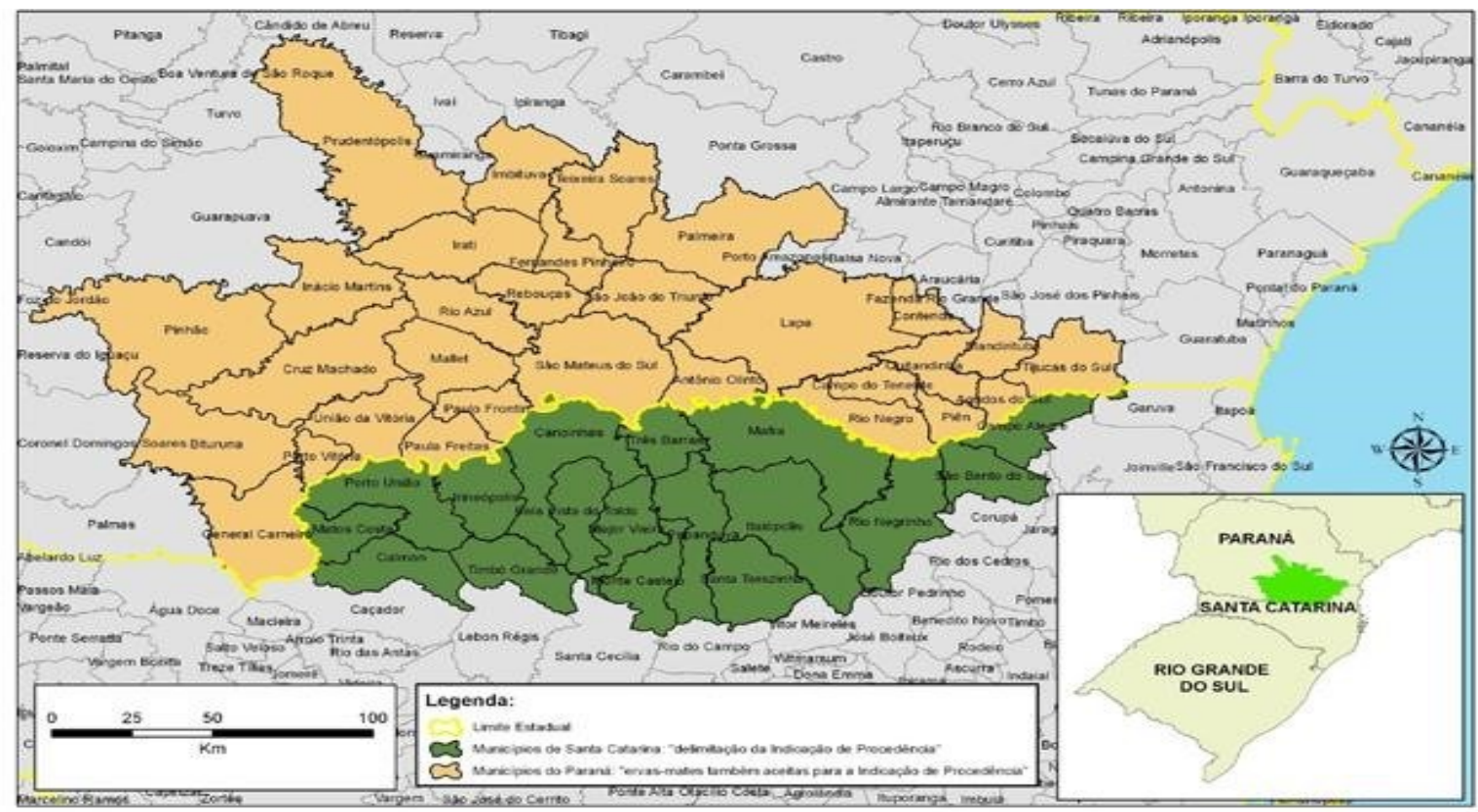

Fonte: Epagri/Ciram (2016)

Nossa proposição como pesquisadores e estudiosos do tema, é que se tome como recorte territorial objeto da IG da erva-mate, o que passamos a denominar de "Região Ervateira do Médio Vale do Rio Iguaçu", conforme apresentado na Figura 4. Legalmente, tal regionalização ainda não está reconhecida, o que será necessário fazer, para que oficialmente sirva de referência territorial para a estruturação da IG. O médio vale do Iguaçu é o recorte territorial que está demarcado entre as duas linhas pretas. O recorte assinalado coincide aproximadamente o que está demarcado na Figura 3. 
Figura 4 - Mapeamento da Região Ervateira do Médio Vale do Rio Iguaçu

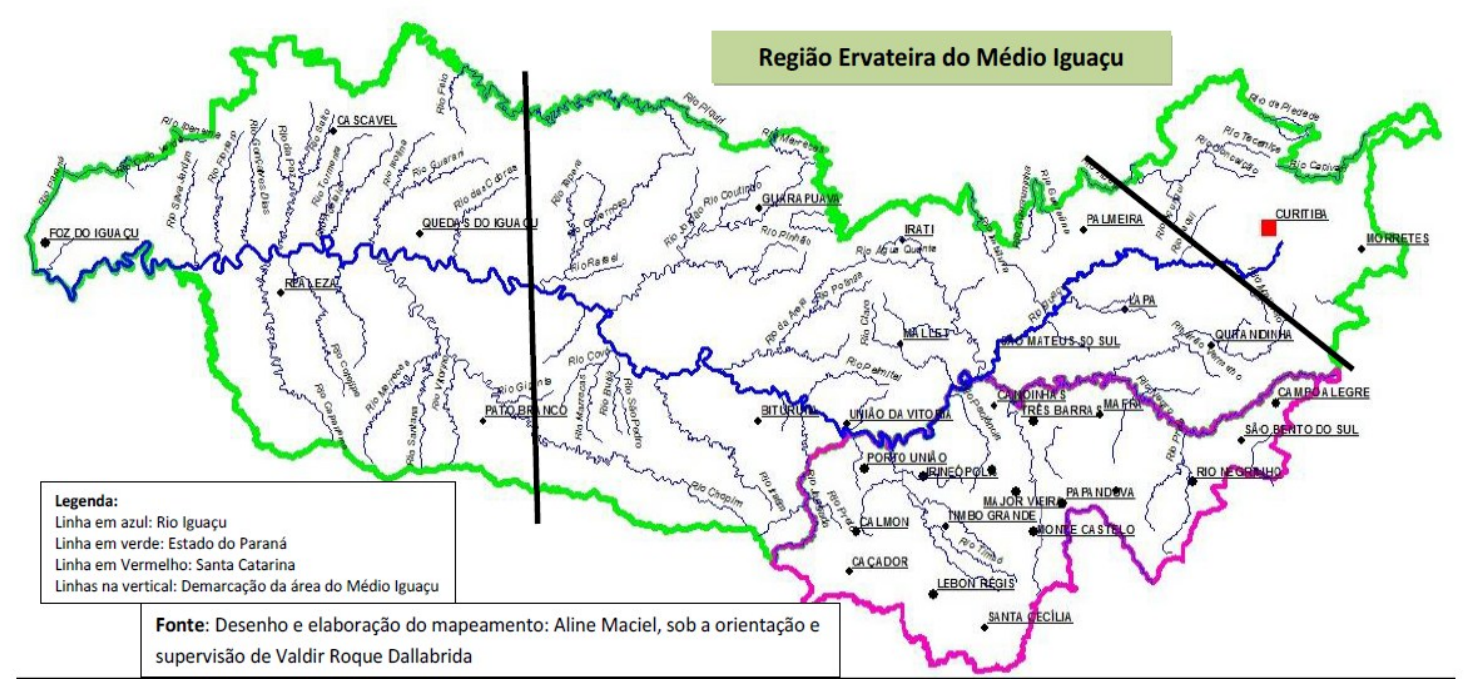

Fonte: Elaboração própria. Desenho: Aline Maciel (2016)

A contribuição deste texto, nas considerações finais, a partir da estrutura de governança da IG Região do Cerrado Mineiro, será fazer analogias e propor indicativos de uma possível estrutura organizacional para a IG da erva-mate aqui referida.

\section{CONSIDERAÇÕES FINAIS}

Considerando a visão de Niederle (2014), afirmando que a construção de uma IG é um processo dinâmico de inovação institucional, no caso da IG da erva-mate, como está ainda na fase de estruturação, tem-se quase tudo a fazer. Partindo do entendimento que a estrutura de governança territorial da experiência de IG Região do Cerrado Mineiro tem algo de inovador em relação a outras experiências similares no Brasil e no mundo, tomaremos a mesma como referência para fundamentar nossas reflexões prospectivas.

Deste modo, baseando-se na estrutura de governança territorial que vem apresentando resultados satisfatórios, o caso do café do cerrado mineiro, propomos uma estrutura de governança para IG da erva-mate. Sabemos que se trata de um exercício de prospecção, como provocação para a reflexão e o aprofundamento de debate regional. Não temos a pretensão de apresentar a estrutura de governança mineira como modelo. Até porque estamos nos referindo a realidades socioeconômicas, culturais e ambientais, além de produto, diferenciadas. No entanto, não se pode negar que existem similaridades, em especial, em relação às exigências organizacionais e de mercado que são comuns às duas experiências.

Veja-se a Figura 5. 
Figura 5 - Estrutura de governança da IG da erva-mate do Médio Vale do Rio Iguaçu-SC e PR

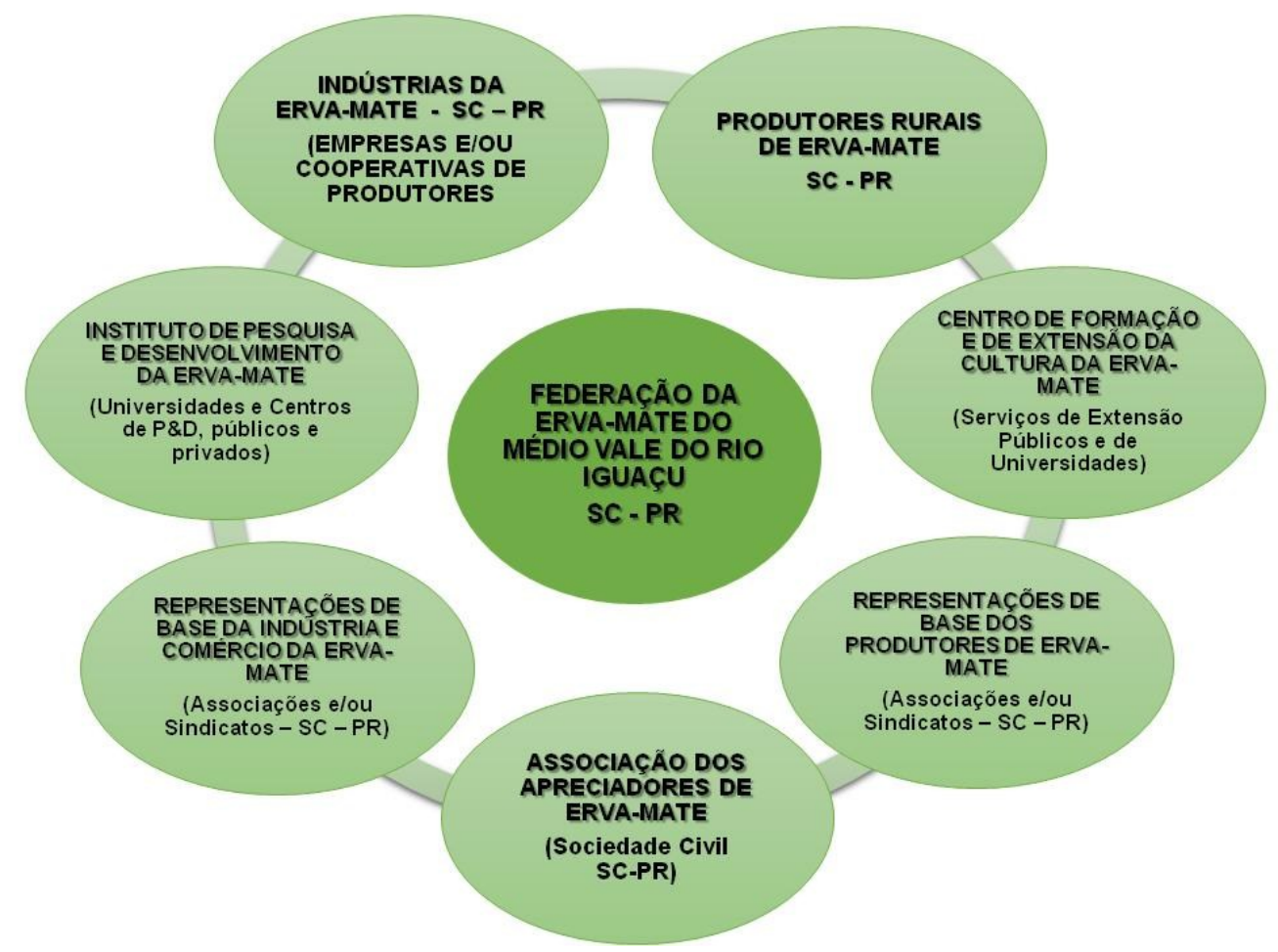

Fonte: Elaboração própria (2016)

Trata-se da prospecção de uma estrutura de governança territorial para a futura IG da erva-mate, fazendo analogias com a da experiência mineira do café. No entanto, para sua efetivação, na nossa perspectiva de pesquisadores, há a necessidade de se arquitetar: (i) representações de base dos produtores de erva-mate, que tenham o produto como uma atividade prioritária ou complementar, na forma de associações; (ii) no caso do setor industrial da erva-mate, apesar da existência do Sindicato das Indústrias do Mate, tanto no Estado de Santa Catarina como no Paraná, considerando a estrutura como estão organizados os sindicatos, questiona-se se essa seria forma adequada de organização; entendemos que uma nova associação das indústrias das regiões envolvidas, nos dois estados, seria preferível; (iii) quanto à estrutura de comercialização da erva-mate, no momento, isso só ocorre por meio de empresas, com exceção de uma cooperativa no município de Campo Alegre; dessa forma os produtores rurais, ficam totalmente dependentes do setor empresarial na fixação de preços da matéria-prima; sugere-se, a exemplo da experiência do Café do Cerrado Mineiro, duas iniciativas, primeiro, que os produtores da região se organizem em associações e reflitam sobre a possibilidade de criação de cooperativas, com fins de comercialização, e/ou beneficiamento; o modelo de cooperativas, poderia seguir a experiência das cooperativas descentralizadas, conforme já ocorre com produtores familiares do sul e oeste de Santa Catarina $^{16}$; (iv) por outro lado, seria da maior valia, uma estrutura regional que tenha envolvimento na pesquisa e desenvolvimento de novos produtos, estudos de base, além da necessidade de ampliar o assessoramento técnico aos produtores rurais; essa estrutura, poderia/deveria envolver as universidades regionais e os órgãos públicos de pesquisa e

\footnotetext{
${ }^{16}$ Sobre o tema, ver Estevam e Mior (2014).
} 
extensão, a exemplo da Embrapa Florestas, o MAPA e a Epagri, podendo ser gerida por uma fundação, a exemplo da experiência do café do cerrado mineiro.

Ressalte-se, finalmente, que devido à amplitude do território em referência, o que apresenta maiores desafios quanto à articulação, exige-se uma estrutura de governança multinível (envolvendo instâncias representativas de caráter local, regional, estadual e interestadual) e multiescalar (atingindo representações interestaduais, nacionais e até internacionais). Portanto, estes aspectos denotam estarmos nos referindo a uma experiência com alta complexidade quanto ao aspecto organizacional. Finalmente, o desafio principal, será, no decurso do processo final de estruturação da experiência, conseguir envolver todos os elos da cadeia produtiva da erva-mate, nos dois estados, Santa Catarina e Paraná.

\section{REFERÊNCIAS}

DALLABRIDA, V. R. Governança territorial: do debate teórico à avaliação da sua prática. Análise Social, v. 50(2º, n. 215, p. 304-328, 2015.

. Ativos Territoriais, Estratégias de Desenvolvimento e Governança Territorial: uma análise comparada de experiências brasileiras e portuguesas. Revista EURE, n. 126, p. 187212, maio 2016.

. et al. Indicação Geográfica da Erva Mate no Território do Contestado: reflexões e projeções. Desenvolvimento Regional em debate, v. 4, n. 2, p. 44-77, jul./dez. 2014.

Território, governança e desenvolvimento territorial: indicativos teóricometodológicos, tendo a Indicação Geográfica como referência. São Paulo: LiberArs, 2016.

FARINÓS, J. Gobernanza territorial para el desarrollo sostenible: estado de la cuestión y agenda. Boletín de la A. G. E., n. 46, p. 11-32, 2008.

FERRÃO, J. Governança, governo e ordenamento do território em contextos metro-politanos. FERREIRA, A.; RUA, J.; MARAFON, G. J.; SILVA, A. C. P. (Eds.). Metropolização do espaço: gestão territorial e relações urbano rural. Rio de Janeiro, Consequência, 2013. p. 255282.

KAZANCIGIL, A. A regulação social e a governança democrática da mundialização. In: MILANI, V. et al. (Orgs.). Democracia e Governança Mundial: que regulações para o Século XXI?. Porto Alegre, Editora Universidade/UFRGS/UNESCO, 2002, p. 47-62

MINISTERIO DA AGRICULTURA. Indicação Geográfica. Disponível em: $<\mathrm{http}$ :/www.agricultura.gov.br/desenvolvimento -sustentavel/indicação geografica $>$ Acesso em: 17 jun. 2016.

MOULAERT, F.; PARRA, C.; SWYNGEDOUW, E. Ciudades, barrios y gobernanza multiescalar en la Europa urbana. Revista EURE, v. 40, n. 119, p. 5-24, enero 2014. 
NIEDERLE, P. A. Desenvolvimento, Instituições e Mercados Agroalimentares: os usos das Indicações Geográficas. Desenvolvimento Regional em debate, v. 4, n. 2, p. 21-43, jul./dez. 2014.

PEREIRA, M. Governança Territorial Multinível: fratura(s) entre teoria e prática(s).

Desenvolvimento Regional em debate, v. 4, n. 2, p. 4-20, jul./dez. 2014.

PIMENTEL, Luiz Otávio. Os desafios dos aspectos legais na prática de estruturação das Indicações Geográficas. In: DALLABRIDA, V. R. Território, identidade territorial e desenvolvimento regional: reflexões sobre Indicação Geográfica e novas possibilidades de desenvolvimento com base em ativos com especificidade territorial. São Paulo: LiberArs, 2013, p. 135-143

RHODES, R. A. W. The New Governance: Governing without Government. Political Studies, n. 44, p. 652-667, 1996.

ROSENAU, J. N.; CZEMPIEL, E-O. (eds.). Governance without Government: Order and Change in World Politic. Cambridge: Cambridge University Press, 1992.

ROMERO, J.; FARINÓS, J. Redescubriendo la gobernanza más allá del buen gobierno. Democracia como base, desarrollo territorial como resultado. Boletín de la A.G.E., v. 56, p. 295-319, 2011.

ESTEVAM, D. O.; MIOR, L. C. Inovações na Agricultura Familiar: as cooperativas descentralizadas em Santa Catarina. Florianópolis: Editora Insular, 2014.

STOKER, G. Governance as a theory. Five propositions". International Social Science Journal, v. 50, n. 155, p. 17-28, 1998.

VANDECANDELAERE, E. et al. (Ed.). Uniendo Personas, Territorios y Productos. Guía para fomentar la calidad vinculada al origen y las indicaciones geográficas sostenibles. Roma: FAO/SINER-GI, 2011 (reimpressão).

\section{Artigo recebido em: 20/06/2016}

Artigo aprovado em: 14/07/2016 